\title{
Left ventricular dysfunction in normotensive type II diabetic patients in Port Harcourt, Nigeria
}

\author{
This article was published in the following Dove Press journal: \\ Vascular Health and Risk Management \\ 24 September 2013 \\ Number of times this article has been viewed
}

\author{
Sotonye T Dodiyi-Manuel' \\ Maclean R Akpa ${ }^{2}$ \\ Osaretin J Odia ${ }^{2}$ \\ 'Department of Medicine, University \\ of Port Harcourt Teaching Hospital, \\ Port Harcourt, Nigeria; ${ }^{2}$ Department \\ of Medicine, Faculty of Clinical \\ Sciences, University of Port Harcourt, \\ Port Harcourt, Nigeria
}

Background: Diabetes mellitus (DM) is on the increase globally. Cardiovascular complications, such as left ventricular dysfunction is a major cause of death in patients with type II DM. Prior to the development of symptomatic heart failure, subclinical left ventricular dysfunction (systolic and diastolic) may exist for some time.

Aim: The aim of the study was to determine the prevalence of left ventricular dysfunction in non-hypertensive type II DM patients.

Methods: A cross sectional study of left ventricular function in 90 normotensive type II diabetes mellitus patients using echocardiography was carried out. Healthy normotensive controls matched for age, sex, and body mass index were selected for comparison. Patients and controls who had hypertension (blood pressure of $>140 / 90 \mathrm{mmHg}$ ), history of smoking, significant alcohol history, pregnancy, features of thyroid disease, or valvular heart disease were excluded. Left ventricular diastolic and systolic functions were assessed.

Results: Ninety patients, (39 males and 51 females) and 90 healthy controls (39 males and 51 females) were enrolled. Mean age of patients was $50.76 \pm 9.13$ years and $51.33 \pm 7.84$ years for controls. Mean body mass index was $26.88 \pm 4.73 \mathrm{~kg} / \mathrm{m}^{2}$ in patients and $27.09 \pm 4.04 \mathrm{~kg} / \mathrm{m}^{2}$ in controls. Mean ejection fraction was $62.4 \% \pm 8.47 \%$ and $68.52 \% \pm 7.94 \%$ in patients and controls, respectively $(P<0.001)$. Fourteen $(15.56 \%)$ patients had ejection fraction less than $55 \%$ compared to four $(4.44 \%)$ in controls $(P<0.001$; odds ratio $=3.96)$. Impaired diastolic function was found in $65.6 \%$ of patients compared to $3.3 \%$ of controls $(P<0.001)$. Left ventricular mass index of $>99 \mathrm{~kg} / \mathrm{m}^{2}$ in females and $>115 \mathrm{~kg} / \mathrm{m}^{2}$ in males was considered abnormal. The left ventricular mass index was also higher in patients than in controls $\left(95.17 \pm 25.67 \mathrm{~g} / \mathrm{m}^{2}\right.$ versus $\left.85.40 \pm 18.0 \mathrm{~g} / \mathrm{m}^{2} ; P=0.004\right)$.

Conclusion: Normotensive diabetic patients have a high prevalence of left ventricular dysfunction even in the absence of cardiac symptoms.

Keywords: type II diabetes mellitus, diastolic dysfunction, systolic dysfunction

\section{Introduction}

The prevalence of diabetes mellitus (DM) is increasing globally. ${ }^{1,2}$ It is projected that 366 million people will be diabetic in 2030, 290 million of whom will be living in developing countries. ${ }^{3,4}$ In Nigeria, the prevalence of DM is between $6 \%$ and $6.8 \%$ in urban areas. ${ }^{5,6}$ Type II DM is a risk factor for cardiovascular disease and cardiovascular complications are a major cause of mortality and morbidity in diabetic patients. ${ }^{7}$ Left ventricular dysfunction, increased left ventricular wall thickness, increased left ventricular mass, and specific diabetic cardiomyopathy are some of the cardiovascular complications associated with diabetes. ${ }^{8}$ Left ventricular diastolic dysfunction has been
Correspondence: Sotonye T Dodiyi-Manuel Department of Medicine, University of Port Harcourt Teaching Hospital, PMB 6I73, Port Harcourt, Nigeria Email tbtspecial@yahoo.com 
demonstrated in diabetic patients who are normotensive and have no symptoms of cardiac disease. ${ }^{9,10}$ Increased mortality among type II diabetic patients with heart failure with normal ejection fraction also suggests a role for diastolic heart failure. ${ }^{11}$

The aim of this study was to determine the prevalence of left ventricular dysfunction in diabetic patients and to compare it with that of healthy adult Nigerians in Port Harcourt, southern Nigeria.

\section{Methodology}

A cross sectional study was undertaken among type II diabetic patients attending the Medical Outpatient Department of the University of Port Harcourt Teaching Hospital. All type II DM patients with normal blood pressure (blood pressure $<140 / 90 \mathrm{mmHg})^{12}$ and were not on anti-hypertensive medications who gave informed consent were recruited into the study. An equal number of apparently healthy adults matched for age, sex, and body mass index were recruited for comparison. Height in meters was measured using a Stadiometer with subjects standing feet together without shoes or headgear, back and heel together against a vertical ruled bar to which a movable attached horizontal bar was brought to the vertex of the patients head and reading taken to the nearest 0.5 centimeter. Weight was taken using a weighing scale with the subject wearing only light clothing. The scale used was standardized against a fixed weight every ten readings.

Body mass index was defined as weight in kilograms divided by the square of the height in meters $\left(\mathrm{kg} / \mathrm{m}^{2}\right)$. Waist and hip circumference were measured in cm using a tape measure. Waist circumference was taken at the part of the trunk located midway between the costal margin and the iliac crests with the subject standing with feet about $25-30 \mathrm{~cm}$ apart. $^{13}$

The tape was fitted snugly without compressing underlying soft tissue and circumference was measured to the nearest $0.5 \mathrm{~cm}$ at the end of a normal expiration. Hip circumference was taken at the level of the greater trochanters. The waist to hip ratio was calculated.

Blood sugar was analyzed using glucose oxidase method.

All patients and control subjects had trans thoracic echocardiographic evaluation using an ALOKA $^{\mathrm{R}}$ SSD 400 machine (Fair Medical Company Ltd., Matsudo, Japan). Echocardiography was done in standard views and measurements taken in accordance with the American Society of Echocardiography guidelines. ${ }^{14}$ The views and measurements were undertaken by two observers conversant with echocardiographic procedures. The left ventricular systolic function measurement was based on the Teichoiz method while diastolic function was based on the Doppler recording of left ventricular filling dynamics. The peak velocities of left ventricle filling during the early rapid (E wave $\mathrm{m} / \mathrm{seconds}$ ) and atrial contraction (A wave, $\mathrm{m} / \mathrm{second}$ ) phases, the ratio of the two filling velocities (E/A ratio), E wave deceleration time (DT in milliseconds) from the peak of the E wave to the portion at which the deceleration velocity reaches the baseline and the isovolumic relaxation time (IVRT milliseconds), the time from aortic valve closure to the beginning of the $\mathrm{E}$ wave were all recorded at the end of expiration for five consecutive beats. Valsalva maneuver was performed to unmask pseudo normal filling. Patients were directed to perform a standard valsalva maneuver by holding a breath and bearing down against a closed glottis at the same time for at least 10 seconds. All diastolic indices were recorded again in the second phase of the valsalva maneuver. Patients who had valvular abnormalities or wall motion abnormalities were excluded from the study. Patients were graded into abnormal relaxation, pseudo normal filling, and restrictive filling. Left ventricular mass index was also assessed. Left ventricular mass index (LVMI) of $>99 \mathrm{~kg} / \mathrm{m}^{2}$ in females and $>115 \mathrm{~kg} /$ $\mathrm{m}^{2}$ in males was considered abnormal. ${ }^{14}$

All data obtained were analyzed using SPSS version 15.0 (IBM Corporation, Armonk, NY, USA). The results are presented as means \pm standard deviation, percentages, and tables. Continuous variables were compared using the Student's $t$ - test, while categorical parameters were analyzed with the Chi-square test or two tailed Fischer's exact test as appropriate. A $P$-value of 0.05 or less was considered statistically significant.

\section{Results}

There were 90 patients ( 39 males and 51 females) with male to female ratio of $2: 3$. The age range was $36-65$ years with a mean age of $50.76 \pm 9.13$ years. The age range of the controls was $35-60$ years with mean age of $51.33 \pm 7.84$ years. There was no significant difference between mean ages of patients and controls $(P=0.66)$.

The mean duration of diabetes was $3.43 \pm 2.89$ years and $83.3 \%(n=75)$ of patients had diabetes for 5 years or less, while $16.7 \%(n=15)$ had diabetes for more than 5 years. The most frequently prescribed anti-diabetic treatment was diet and oral hypoglycemic agents in $72(80 \%)$ patients. The majority of patients were on oral hypoglycemic agents, biguanides, and sulphonylureas. Only two patients $(2.2 \%)$ 
were on diet and lifestyle measures alone while 16 (17.8\%) were on diet, oral hypoglycemic agents, and insulin.

The mean systolic and diastolic blood pressures were normal in both patients and controls. The mean body mass index in both groups showed that they were overweight but there was no statistically significant difference between the two groups (Table 1).

The patients had a normal but significantly lower mean ejection fraction than the controls $(62.4 \% \pm 8.47 \%$ versus $68.52 \% \pm 7.94 \%$, respectively; $P<0.001)$ as shown in Table 2. Fourteen patients (15.6\%) and four (4.4\%) controls had depressed ejection fraction $<55 \%(P=0.013$; odds ratio $=3.96)$. The mean fractional shortening was $33.76 \% \pm 6.20 \%$ in patients and $38.22 \% \pm 6.10 \%$ in controls Eleven (12.2\%) of the patients and two (2.2\%) controls had abnormal fractional shortening ( $<25 \%$ in males and $<27 \%$ in females; $P<0.001$ ).

The mean early to late diastolic filling ratio (E/A ratio) in subjects was $1.03 \pm 0.37$ and $1.44 \pm 0.29$ in controls $(P<0.001)$. Left ventricular diastolic filling pattern was abnormal in $59(65.6 \%)$ patients and three $(3.3 \%)$ controls $(P<0.001)$. Fifty two $(57.8 \%)$ patients and three $(3.3 \%)$ controls had a reversed E/A ratio. Six (6.7\%) patients and one $(1.1 \%)$ control had a pseudo normal filling pattern. A restrictive pattern was seen in one patient but none in the controls (Table 4). The mean isovolumic relaxation time was $124.91 \pm 34.18$ seconds in the subjects and $114.56 \pm 23.64$ seconds in the controls and this difference was statistically significant $(P<0.001)$. The mean relative wall thickness was higher in patients than controls $0.475 \pm 0.09$ versus $0.405 \pm 0.07$, respectively, and this difference was statistically significant $(P<0.001)$. The mean LVMI was significantly higher in patients $\left(95.17 \pm 5.67 \mathrm{~g} / \mathrm{m}^{2}\right)$ compared to controls $\left(85.40 \pm 18.0 \mathrm{~g} / \mathrm{m}^{2} ; P=0.004\right.$; Table 2$)$.

Forty five (50\%) patients had abnormal LVMI while 23 (25.6\%) controls had abnormal LVMI and this difference was statistically significant $(P<0.001$; Table 3$)$.

Table I Demographic characteristic in subjects and controls

\begin{tabular}{lcccc}
\hline Variable & Subjects & Controls & t-test & $P$-value \\
\hline $\begin{array}{l}\text { Mean age } \\
\text { (years) }\end{array}$ & $50.76 \pm 9.13$ & $51.33 \pm 7.84$ & 0.460 & 0.66 \\
$\begin{array}{l}\text { Mean BMI } \\
\left(\mathrm{kg} / \mathrm{m}^{2}\right)\end{array}$ & $26.88 \pm 4.73$ & $27.09 \pm 4.04$ & 0.330 & 0.74 \\
$\begin{array}{l}\text { Mean SBP } \\
(\mathrm{mmHg})\end{array}$ & $113.87 \pm 10.27$ & $117.93 \pm 8.81$ & 2.850 & 0.005 \\
$\begin{array}{l}\text { Mean DBP } \\
(\mathrm{mmHg})\end{array}$ & $70.87 \pm 7.34$ & $64.64 \pm 8.80$ & 0.036 & 0.036 \\
\hline
\end{tabular}

Abbreviations: BMI, body mass index; DBP, diastolic blood pressure; SBP, systolic blood pressure.
Table 2 Indices of left ventricular structure and function in subjects and controls

\begin{tabular}{lccl}
\hline Indices & Subjects & Control & $P$-value \\
\hline Mean E/A ratio & $1.03 \pm 0.37$ & $1.44 \pm 0.29$ & 0.00 \\
Mean IVRT (milliseconds) & $124.91 \pm 34.18$ & $114.56 \pm 23.64$ & 0.01 \\
Mean DT (milliseconds) & $218.49 \pm 48.83$ & $212.97 \pm 35.34$ & 0.38 \\
Mean E (cm/second) & $68.57 \pm 16.01$ & $78.16 \pm 15.31$ & 0.00 \\
Mean A (cm/second) & $69.17 \pm 14.67$ & $53.31 \pm 11.46$ & 0.00 \\
Mean EF (\%) & $62.40 \pm 8.47$ & $68.52 \pm 7.94$ & 0.00 \\
Mean FS (\%) & $33.76 \pm 6.20$ & $38.22 \pm 6.10$ & 0.00 \\
Mean LVMI (kg/m $)$ & $95.17 \pm 25.67$ & $85.40 \pm 18.0$ & 0.004 \\
Mean RWT & $0.475 \pm 0.09$ & $0.405 \pm 0.07$ & 0.00 \\
\hline
\end{tabular}

Abbreviations: $E$, peak velocity of early left ventricular filling; A, peak velocity of atrial contraction; DT, deceleration time; EF, ejection fraction; FS, fractional shortening; IVRT, isovolumetric relaxation time; LVMI, left ventricular mass index, RWT, relative wall thickness.

The mean fasting blood sugar was $7.673 \mathrm{mmols} / \mathrm{L}$ in patients and $4.830 \mathrm{mmols} / \mathrm{L}$ in controls and this difference was statistically significant $(P \leq 0.05)$.

\section{Discussion}

The role of elevated blood sugar in the causation of various cardiovascular diseases has been investigated by several researchers. ${ }^{9}, 15,16$ These studies have shown that DM causes structural and functional abnormalities that are independent of the effect of atherosclerosis and these abnormalities contribute significantly to adverse cardiovascular events. ${ }^{8}$ Chronic hyperglycemia in DM expresses its toxicity by forming non-enzymatic glycation of tissue macromolecules, such as proteins, lipids, and deoxyribonucleic acid (DNA) to form irreversibly bound advanced glycated end products. ${ }^{17}$ Such products have been found to accumulate in tissues such as the heart. ${ }^{18}$ The DM patients in our study had thicker mean interventricular septal thickness in diastole and left ventricular posterior wall thickness in diastole compared to controls $(P<0.001$ for both). Abnormalities in cardiac structure of diabetic patients included a significant increase in LVMI and relative wall thickness compared to normal controls. The LVMI also increased in 45 (50\%) patients compared to 23 (25.6\%) controls $(P<0.001)$. This change in cardiac structure has been postulated to be due to deposition of glycoprotein,

Table 3 Comparison of number of patients and controls with normal and abnormal left ventricular mass index

\begin{tabular}{llllll}
\hline Study & LVMI & & X $^{2}$ & P-value & OR \\
\cline { 2 - 3 } status & Abnormal & Normal & & & \\
\hline Patient & $45(50 \%)$ & $45(50 \%)$ & 11.4 & $0.0007^{*}$ & 2.91 \\
Control & $23(25.6 \%)$ & $67(74.4 \%)$ & & & \\
\hline
\end{tabular}

Note: *P-value $\leq 0.05$ is statistically significant.

Abbreviations: OR, odds ratio; LVMI, left ventricular mass index. 
Table 4 Comparison of number of patients and controls with normal and abnormal diastolic filling pattern

\begin{tabular}{lclll}
\hline $\begin{array}{l}\text { Filling } \\
\text { pattern }\end{array}$ & Patient & Control & $\mathbf{X}^{2}$ & P-value \\
\hline $\begin{array}{l}\text { Normal } \\
(\text { E/A }>1)\end{array}$ & $31(34.4 \%)$ & $87(96.7 \%)$ & 77.16 & $0.00 *$ \\
$\begin{array}{l}\text { Abnormal } \\
\text { Relaxation }\end{array}$ & $52(57.8 \%)$ & $2(2.2 \%)$ & 1.44 & 0.510 \\
$\begin{array}{l}\text { E/A }<1) \\
\text { Pseudonormal }\end{array}$ & $6(6.7 \%)$ & $1(1.1 \%)$ & 3.66 & 0.118 \\
$\begin{array}{l}\text { Restrictive } \\
(\text { E/A }>2)\end{array}$ & $1(1.1 \%)$ & $0(0 \%)$ & 1.01 & 1.000 \\
\hline
\end{tabular}

Abbreviations: E/A, the ratio of peak velocities of early left ventricular filling to peak velocity of atrial contraction.

Note: $*$ significant $P$ value: $P \leq 0.05$.

fibrosis, and presence of microangiopathy. ${ }^{8,19}$ In the diabetic heart, there is an increase in apoptosis leading to increased collagen deposition in a diffuse manner as a result of replacement fibrosis and connective tissue proliferation. Ultimately there is decreased ventricular compliance. ${ }^{20}$ Left ventricular diastolic dysfunction has been proposed to be the first stage of the putative "diabetic cardiomyopathy". ${ }^{21}$ A reduced E/A ratio has been shown to be independently associated with increased all-cause mortality as well as cardiovascular mortality. ${ }^{22}$ These structural abnormalities may lead to increased wall stress, increased oxygen demand, ischemia, and the development of left ventricular diastolic dysfunction. ${ }^{8}$ The prevalence of left ventricular diastolic dysfunction in these normotensive and asymptomatic diabetics without previous history of cardiac disease was quite high compared to controls (65.6\% versus $3.3 \%$ ) but is comparable to findings by other workers using similar Doppler methods for assessing left ventricular function. ${ }^{17-24}$ Furthermore, in this study, of the $65.5 \%$ diabetic patients with diastolic dysfunction, 57.8\% had impaired relaxation, $6.7 \%$ had pseudo normal filling, and 1.1\% had restrictive filling pattern. Valsalva maneuver was used to unmask pseudo normal filling. In the control group, three had impaired relaxation while only one subject had pseudo normal diastolic filling pattern. These results were similar to the findings of other workers. In the study by Ojji et $\mathrm{al}^{21}$ of the $71 \%$ of diabetic patients who had diastolic dysfunction, $58 \%$ had impaired relaxation, $7 \%$ had pseudo normal filling, and $6 \%$ had restrictive filling. They did not assess systolic dysfunction. Poirer et $\mathrm{al}^{19}$ found a prevalence of diastolic dysfunction of $60 \%$ when they studied 46 normotensive type II DM patients and 15 (32\%) had impaired relaxation while $13(28 \%)$ had pseudo normalized filling. Zabalgoiha et al, ${ }^{22}$ however, found diastolic dysfunction in $47 \%$ of patients, while Boyer et $\mathrm{al}^{10}$ found that the prevalence of diastolic dysfunction was $75 \%$ because of the use of tissue Doppler imaging, which increased the detection of diastolic dysfunction.

The present study also demonstrated a significant reduction in mean left ventricular ejection fraction in diabetics compared to healthy controls $(62.2 \%$ versus $68.5 \%$; $P<0.001$ ), although the mean values were normal in both groups. This significant reduction in mean ejection fraction signifies early left ventricular systolic dysfunction in these diabetic patients despite absence of symptoms of cardiovascular disease. A reduced ejection fraction $(<55 \%)$ of $15.65 \%$ was found in diabetics compared to only $4.4 \%$ of control subjects. The findings of systolic dysfunction and increased prevalence of diastolic dysfunction has also been previously demonstrated. ${ }^{9}$ Diastolic dysfunction was found in $3.3 \%$ of controls. This is probably because overweight and obese controls, who had to be matched with the overweight and obese in the diabetic group, were used in the study. Obesity is known to increase the risk of diastolic dysfunction and increase LVMI. This study is, however, different from most previous studies in Nigeria as it excluded hypertensive diabetic patients and assessed both systolic and diastolic function. Patients were also closely matched with controls for age, sex, and body mass index. The patients in this study were asymptomatic with short duration of DM (mean duration of diabetes was 3 years). This showed that even early in the diagnosis of type II DM left ventricular dysfunction exists.

\section{Conclusion}

Left ventricular dysfunction is prevalent among type II diabetic patients in Port Harcourt, Nigeria without symptomatic heart disease. Echocardiography is of immense benefit in the management of type II DM patients as this will enhance early detection of left ventricular dysfunction with a view to early treatment in order to reduce morbidity and mortality.

\section{Limitations of the study}

1. Stress electrocardiography, stress echocardiography, myocardial perfusion imaging, and coronary angiography were not used to exclude sub clinical coronary disease; and

2. A larger number of subjects may be required to draw definitive conclusions.

\section{Recommendations}

1. It is necessary to screen diabetics early for sub clinical left ventricular dysfunction which may be present even in 
patients with short duration of DM as seen in this study; and

2. There is a need for early commencement of treatments, such as angiotensin receptor blockers or angiotensin converting enzyme inhibitors, when subclinical left ventricular dysfunction is detected to prevent the development of symptomatic left ventricular dysfunction.

\section{Disclosure}

Authors declare no conflicts of interest in this work.

\section{References}

1. Zimmet PZ, McCarty DJ, de Courten MP. The global epidemiology of non-insulin-dependent diabetes mellitus and the metabolic syndrome. J Diabetes Complicat. 1997;11(2):60-68.

2. Murray CJL, Lopez AD, editors. The global burden of disease a comprehensive assessment of mortality and disability, diseases injuries and risk factors in 1990 and projected to 2020. Geneva: World Health Organization; 1996.

3. Wild S, Roglic G, Green A, Sicree R, King H. Global prevalence of diabetes: estimates for the year 2000 and projections for 2030. Diabetes Care. 2004;27(5):1047-1053.

4. Sobngwi E, Mauvais-Jarvis F, Vexiau P, Mbanya JC, Gautier JF. Diabetes in Africans. Part 1: epidemiology and clinical specificities. Diabetes Metab. 2001;27(6):628-634.

5. Owoaje EE, Rotimi CN, Kaufman JS, Tracy J, Cooper RS. Prevalence of adult diabetes in Ibadan, Nigeria. East Afr Med J. 1997;74(5): 299-302.

6. Nyenwe EA, Odia OJ, Ihekwaba AE, Ojule A, Babatunde S. Type 2 diabetes in adult Nigerians: a study of its prevalence and risk factors in Port Harcourt, Nigeria. Diabetes Res Clin Pract. 2003;62(3):177-185.

7. Herlitz J, Malmberg K. How to improve the cardiac prognosis for diabetes. Diabetes Care. 1999;22 Suppl 2:B89-B96.

8. Devereux RB, Roman MJ, Paranicas M, et al. Impact of diabetes on cardiac structure and function: the strong heart study. Circulation. 2000;101(19):2271-2276.

9. Danbauchi SS, Anumah FE, Alhassan MA, David SO, Onyemelukwe GC, Oyati IA. Left ventricular function in type 2 diabetes patients without cardiac symptoms in Zaria, Nigeria. Ethn Dis. 2005;15(4): 635-640.

10. Boyer JK, Thanigaraj S, Schechtman KB, Pérez JE. Prevalence of ventricular diastolic dysfunction in asymptomatic, normotensive patients with diabetes mellitus. Am J Cardiol. 2004;93(7):870-875.

11. Owan TE, Hodge DO, Herges RM, Jacobsen SJ, Roger VL, Redfield MM. Trends in prevalence and outcome of heart failure with preserved ejection fraction. $N$ Engl J Med. 2006;355(3):251-259.
12. Chobanian AV, Bakris GL, Black HR, et al; Joint National Committee on Prevention, Detection, Evaluation, and Treatment of High Blood Pressure. National Heart, Lung, and Blood Institute; National High Blood Pressure Education Program Coordinating Committee. Seventh report of the Joint National Committee on Prevention, Detection, Evaluation, and Treatment of High Blood Pressure. Hypertension. 2003;42(6): $1206-1252$.

13. Douketis JD, Paradis G, Keller H, Martineau C. Canadian guidelines for body weight classification in adults: application in clinical practice to screen for overweight and obesity and to assess disease risk. CMAJ. 2005;172(8):995-998.

14. Lang RM, Bierig M, Devereux RB, et al; European Association of Echocardiography. Recommendations for chamber quantification: a report from the American Society of Echocardiography's Guidelines and Standards Committee and the Chamber Quantification Writing Group, developed in conjunction with the European Association of Echocardiography, a branch of the European Society of Cardiology. $J$ Am Soc Echocardiogr. 2005;18(12):1440-1463.

15. Kannel WB, Hjortland M, Castelli WP. Role of diabetes in congestive heart failure: the Framingham study. Am J Cardiol. 1974;34(1): 29-34.

16. Chaturvedi N, McKeigue PM, Marmot MG, Nihoyannopoulos P. A comparison of left ventricular abnormalities associated with glucose intolerance in African Caribbeans and Europeans in the UK. Heart. 2001;85(6):643-648.

17. Brownlee M. Advanced protein glycosylation in diabetes and aging. Annu Rev Med. 1995;46:223-234.

18. Schleicher ED, Wagner E, Nerlich AG. Increased accumulation of the glycoxidation product $\mathrm{N}($ epsilon)-(carboxymethyl)lysine in human tissues in diabetes and aging. J Clin Invest. 1997;99(3):457-468.

19. Poirier P, Bogaty P, Garneau C, Marois L, Dumesnil JG. Diastolic dysfunction in normotensive men with well-controlled type 2 diabetes: importance of maneuvers in echocardiographic screening for preclinical diabetic cardiomyopathy. Diabetes Care. 2001;24(1):5-10.

20. Weber KT, Brilla CG. Pathological hypertrophy and cardiac interstitium. Fibrosis and renin-angiotensin-aldosterone system. Circulation. 1991;83(6):1849-1865.

21. Ojji D, Parsonage W, Dooris M, et al. Left ventricular diastolic function in normotensive type-2 diabetic subjects. J Natl Med Assoc. 2008;100(9):1066-1072.

22. Zabalgoitia M, Ismaeil MF, Anderson L, Maklady FA. Prevalence of diastolic dysfunction in normotensive, asymptomatic patients with well-controlled type 2 diabetes mellitus. Am J Cardiol. 2001;87(3): 320-323.

23. Poulsen MK, Henriksen JE, Dahl J, et al. Left ventricular diastolic function in type 2 diabetes mellitus: prevalence and association with myocardial and vascular disease. Circ Cardiovasc Imaging. 2010;3(1): 24-31.

24. Rubler S, Dlugash J, Yuceoglu YZ, Kumral T, Branwood AW, Grishman A. New type of cardiomyopathy associated with diabetic glomerulosclerosis. Am J Cardiol. 1972;30(6):595-602.
Vascular Health and Risk Management

\section{Publish your work in this journal}

Vascular Health and Risk Management is an international, peerreviewed journal of therapeutics and risk management, focusing on concise rapid reporting of clinical studies on the processes involved in the maintenance of vascular health; the monitoring, prevention and treatment of vascular disease and its sequelae; and the involvement of

\section{Dovepress}

metabolic disorders, particularly diabetes. This journal is indexed on PubMed Central and MedLine. The manuscript management system is completely online and includes a very quick and fair peer-review system, which is all easy to use. Visit http://www.dovepress.com/ testimonials.php to read real quotes from published authors. 